The Judiciary

For the Chief Justice

The Chief Justice of the United States

Washington, DC 20543

Dear Chief Justice

\section{For an Associate Justice}

Justice (last name)

The Supreme Court of the United States

Washington, D.C. 20543

Dear Justice (last name)

Cabinet Members, Under Secretaries, and Deputy Secretaries of Executive

Departments

The Honorable (name without prefix of Mr.

Dr., Ms., etc.)

The (Title)

Washington, DC (zip code of the department, if available)

Dear (Mr. or Madam) (last name):

\section{Chairman, Director, or Commissioner of} Government Office

The Honorable (name without prefix of $\mathrm{Mr}$., Dr., Ms., etc.)

(Title)

(Agency or office)

Washington, DC (Zip Code)

Dear (Mr. or Madam) (Title)

For contacts at the state government level, use the above, substituting the name of the state for "U.S." or "United States" and the state capital for "Washington, D.C." A directory listing of more specific addresses is usually available upon request to the state governor's office or the clerk of the state legislature at the state capital.

The above is based largely on a publication entitled A Guide for Providing Scientific Testimo$n y$ by Arthur Jack Grimes, Head, Department of Public Responsibilities, American Institute of Biological Sciences.

\section{Advocacy and the American Geophysical Union}

The American Geophysical Union is an association of scientists, scholars, and interested lay public for the purpose of advancing geophysical science. The Union shares a collateral sense of responsibility to assure that the results of geophysical research are made available to benefit all mankind. The Union encourages its members to exercise their individual sense of responsibility in addressing political and social issues. Should they choose to act collectively on such issues, other organizations exist for such purposes. The American Geophysical Union, as a society, should preserve its unique position as an objective source of analysis and commentary for the full spectrum of geophysical science. Accordingly, the following policies should guide the American Geophysical Union's role as an advocate:

- The American Geophysical Union has a responsibility to its members to adopt a position of advocacy on geophysical science issues based on their intrinsic merits and needs.

- To the extent that the understanding and application of geophysical science is relevant to public policy, AGU as a responsible scientific association should make relevant information available to all parties interested in the issue.

- As a scientific society, AGU should not take or advocate public positions on judgmental issues that extend beyond the range of available geophysical data or recognized norms of legitimate scientific debate. Public positions adopted by AGU and statements is sued on its behalf must be based on sound scientific issues and should reflect the interests of the Union as a whole.
- Any individual member may present a position of the Union that has been adopted in accord with procedures approved by the Council of the Union. Individuals presenting an AGU statement shall identify any personal interpretation or expansions of it as their own

Nothing in this policy should prevent individual $A G U$ members from independently carrying out advocacy activity that does not purport to represent AGU or its members.

\section{Procedure for Developing Union Positions}

1. Position statements will be restricted to those issues which fall within the guidelines approved by the Council.

2. Requests for position statements are referred immediately to the Public Affairs Committee.

3. If a request seems to fall within Union guidelines, the committee will recommend that the President of the Union appoint an independent panel charged with drafting a statement. The panel will include at least one member nominated by the Public Affairs Committee, the originator of the request, and one member of Council.

4. The Council and the membership will be informed that the panel is working on the issue and that comments are welcome.

5. The panel will prepare a statement for circulation to the Council of the Union.

6. Members of Council (or Executive Committee when timeliness is critical) will be asked to vote or to comment on the proposed statement. This vote is to be taken at regularly scheduled meetings except where timeliness is critical. Concurrence of two thirds is required for adoption.

7. All adopted position statements will be published in Eos as soon as possible.

8. Once a statement has been approved, the Public Affairs Committee will endeavor to apply its expertise to making advocacy of its contents as effective as possible.

\title{
AGU STYLE A Guide for Contributors
}

\author{
PAGES 743-755
}

Style to be good must be clear, as is proved by the fact that speech which fails to convey a plain meaning will fail to do just what speech has to do. . . Clearness is secured by using the words... that are current and ordinary.

Copyright 1984 by the American Geophysical Union 2000 Florida Avenue, N.W.

Washington, DC 20009
Telephone: 202-462-6903

TWX 710-822-9300

This document may be freely copied. 


\section{SUMMARY SPECIFICATIONS FOR PAPERS}

The following information is a summary. For further details, see later sections on preparing figures and preparing the manuscript.

\section{Spacing}

Double or (preferably) triple space all copy, including references, title page, abstract, text, notation list, figure captions, and tables. Do not use single spacing or 1.5 spacing. Do not prepare camera-ready copy in the case of author-produced papers until requested by the AGU office.

\section{Paper}

Do not use rag or other textured paper, erasable bond paper, or onionskin paper for any of the copies. A smooth, lightweight paper of the type used for xerography is best. Be sure all copies are legible. Type on one side only.

\section{Margins}

Margins on left should be $4 \mathrm{~cm}$ (1.5 in.); on top, right, and bottom, at least $2.5 \mathrm{~cm}$ ( 1 in.).

\section{Line lengths for automatic typewriters}

If the final, camera-ready copy of author-produced papers will be generated from a word processor or automatic typewriter, use at manuscript stage (except for tables and figure captions) a maximum line length of 49 elitesize characters $\left(10.4 \mathrm{~cm}, 4 \frac{1}{8} \mathrm{in}\right.$.). For Radio Science, Tectonics, Global Biogeochemical Cycles, and Paleoceanography at manuscript stage, use a maximum line length of 42 elitesize characters $\left(9.0 \mathrm{~cm}, 3^{1 / 2} \mathrm{in}\right.$.). Widths for tables and figure captions will be specified when the copy edited manuscript is returned to the author.

All math characters in the manuscript that are available on a standard typewriter must be typewritten. Use math or
Greek fonts when available. Identify the characters in handwritten math, and distinguish between similar looking letters, numbers, and special symbols (whether typed or handwritten) at their first use on each page.

\section{Order of parts}

The order of parts in a paper is title page, abstract (except in comments, replies, and corrections), text, appendixes, notation list, acknowledgments, references, author address list, figure captions list, tables, and figures.

\section{Pagination}

Number each sheet of the manuscript consecutively in the upper right corner beginning with the title page and ending with the last page of tables.

\section{Figure captions}

Do not attach captions to figures. Type all captions together in a double-spaced or triple-spaced list.

\section{Tables}

Type each table double spaced on a separate sheet. Give each table a title, and cite each table in text in numerical order. Each table must have at least two columns, and all columns except the first must have heads.

\section{Figures}

Preferably, figures should be sharp photographs on approximately $21.5 \times 28 \mathrm{~cm}(8.5 \times 11$ in.) paper. On a label, write the first author's name, a few key words of the paper's title, and the figure number, and indicate the top of the figure; attach the label to the back of the figure. Cite each figure in text in numerical sequence.

\section{INTRODUCTION: PUBLISHING WITH AGU}

\section{Exclusive Publication and Copyright Provisions}

AGU considers only original scientific contributions that have not been accepted or published elsewhere and are not under consideration by another publisher. A contribution is considered previously published if its data and conclusions are offered for sale or are generally available in other ways to the public. Regardless of the original publication medium, including print, magnetic tape, or microform, such contributions are not eligible for republication in AGU journals or books.

In order for AGU to publish its journals and books in all their various formats, to grant permission to abstracting and indexing services to cover these publications, to authorize translations and to grant permission for photocopying beyond the limits of fair use, AGU must have clear control of the copyright. The AGU Council has determined that AGU will publish only works for which the author has transferred the copyright to the Union. This restriction does not apply when no copyright exists, such as for official works of the U.S. government or other governments that retain copyright. If possible, U.S. and other government employees should have the copyright transfer signed by a coauthor who is not employed by the government.

Under AGU copyright, authors still retain other proprietary rights such as patent rights. They also have the right to present the material orally in any forum, to reproduce figures, tables, and extracts, properly cited, in any publication, and to deny subsequent commercial use of the paper.

Authors who wish to reproduce in their papers figures, tables, and text excerpts copyrighted by others must submit with their manuscript letters of permission from the copyright owners.

\section{Page Charge Policy}

Page charge income supports rapid publication and broad distribution to libraries and individuals. Authors honoring page charges receive a substantial quantity of reprints at no additional cost. Acceptance for publication 
in AGU journals does not depend on the payment of page charges. However, authors unable to honor page charges must provide final copy for photoreproduction. Authors at institutions which do not honor page charges may purchase reprints at an amount equal to the page charge. (Authors who cannot pay page charges and who reside in countries where producing adequate final copy is impossible should contact AGU for assistance.) Current prices are printed on the inside cover of each issue of the journal. Check a current issue or contact AGU for more information.

\section{Editorial Review}

The journal editor, usually with the assistance of associate editors, obtains peer reviews of all submitted papers. The final decision on the paper lies with the editor. Editors strive for a review time of 2-3 weeks for Geophysical Research Letters and 2 months or less for the other journals. Editors may require reviews of revised papers. After acceptance the paper is sent to AGU headquarters, where it is put into production. The date that the paper was originally received by the journal editor, the date that final revisions (if any) were received, and the date of acceptance are provided by the editor and published with the article.

\section{Choosing a Publication Method}

Each AGU journal publishes papers in one or more of the formats discussed below. Each method is designed to provide rapid, economical publication according to the author's needs. Familiarity with these alternatives will help ensure that the final choice will provide the intended benefits. Please consider your final selection carefully. AGU will copy edit your manuscript according to the production method you chose. Changing options after copy editing will delay publication of your paper as well as increase your costs.

\section{Author check of final manuscript}

Regardless of the production method selected, authors should check the final version of the manuscript carefully. The single greatest source of extra expense in typesetting is author corrections in proof of references and citations. "In press" entries in the reference list should be updated (with the date of revision noted at the top of the list), all partial entries should be completed, and reference citations in text should be checked for consistency with the reference list (see section below on principles of reference list style).

Authors should also make sure that the accepted manuscript is free of typographical errors and that it adheres to the specifications for manuscripts described in this guide. Failure to meet manuscript specifications may cause the manuscript to be returned to the author for completion prior to copy editing. Typographical errors in the final manuscript may, like reference list updates in proof, result in extremely costly author alterations and increase the possibility of errors in the final printed version.

\section{AGU-produced papers (typeset)}

Submit the paper in double-spaced or triple-spaced manuscript form. AGU copy edits and typesets the paper and sends one set of proofs to the author. Authors must read proofs carefully because they will not be read at AGU.

Once the paper is in proof, authors should make only necessary changes; changes of substance must be approved by the journal editor. Authors will be charged for added copy and for alterations and deletions of original copy.

\section{Author-produced papers (typewritten or typeset)}

Submit the paper in double-spaced or triple-spaced manuscript form. AGU copy edits it (except for Geophysical Research Letters) and returns it to the author with exact instructions for preparing the camera-ready text and figures. The author is responsible for the accuracy and crisp appearance of the camera-ready copy; AGU is responsible for its proper layout and printing. Some AGU journals may require author-produced copy to be typeset to match AGUproduced copy; check with the journal editor's office or AGU for the policy of the journal in question.

To aid in rapid processing and to allow a reduction in page charges, AGU publishes only author-produced papers in Geophysical Research Letters, without copy editing, and limits their length to four printed pages. For cameraready copy that will be generated by a typwriter output device, the length restriction can usually be met if the text of the double-spaced manuscript is less than $300 \mathrm{~cm}$ long; for camera-ready copy that will be set in 11-on-13 point type, the double-spaced manuscript text should be less than $410 \mathrm{~cm}$ long.

\section{Microform supplements}

Authors may reference lengthy supplemental material in the published paper and have the material itself archived with the full paper in the microform edition of the journal. The supplementary material will be filmed exactly as received, without copy editing. AGU will cite the supplementary material in the text that is printed in the journal and describe how to order it.

Submit the copy that is to be filmed, clearly marked as such, along with the double-spaced or triple-spaced manuscript that is to be printed in the journal. Do not include continuous-tone photographs with the supplementary material.

\section{Summary articles}

Most AGU journals offer the option of publishing an abstract and summary of the paper in the print version of the journal; libraries archive the abstract, summary, and full paper in the microform edition of the journal. The full article may be ordered in microfiche by interested readers.

Submit the abstract and summary, clearly marked as such, in double-spaced or triple-spaced manuscript form. The summary and the full paper are subject to peer review. Cite any continuous-tone photographs (photographs containing gray, including extremely fine dot patterns) in the text of the summary, and include them with it (they do not reproduce well in microform); the summary may also include tables and line drawings. AGU will publish the abstract and summary according to the procedures outlined above. 
The full paper, including all tables and line drawings but excluding continuous-tone photographs, must accompany the summary for editorial review; it should be clearly marked for microform publication. The final, accepted typescript of the full paper may be single spaced because it will be filmed exactly as received, without copy editing.

\section{A NOTE ON WRITING STYLE}

Vigorous writing is concise. A sentence should contain no unnecessary words, a paragraph no unnecessary sentences, for the same reason that a drawing should have no unnecessary lines and a machine no unnecessary parts. This requires not that the writer make all his sentences short, or that he avoid all detail and treat his subjects only in outline, but that every word tell.

-William Strunk, Jr., and E. B. White The Elements of Style, third ed., " 1979 Macmillan Publishing Co., Inc. Reprinted with permission.

We have designed this guide to be used by authors in the writing phase to help minimize the delays and costs of reviewing and publishing papers. Although it is the journal editor's role to determine the acceptability of a paper's style, a few words on widely accepted principles of effective writing are in order. We offer these writing guidelines as suggestions, not as rules.

Writing is not easy. The writer must constantly check the words just put on paper against the thought they were meant to convey. At the end of each draft the writer must read the piece again, not with the pride of authorship but with the open yet critical eye of the reader. To communicate and let the work speak for itself, the principles of clarity, simplicity, and precision are most important.

\section{Some Examples of Revision}

Excessive use of nouns, wordiness, and excessive use of the passive voice are among the most common weaknesses of scholarly writing. Many papers could be greatly improved through revisions in these three areas alone.

Excessive use of nouns is a widespread flaw in journalism and scientific and technical works, where readers especially value concise writing. Using a string of nouns to convey a thought may require fewer words than using a verb and noun structure, but lack of a verb can make the thought harder to understand. For instance, the meaning of the phrase "ways to meet standards for air quality" is much easier to grasp than the meaning of the noun string "air quality standard compliance techniques" ("Nouns and Nounery," by Cheryl Reimold, TAPPI Magazine, September 1980, Technical Association of the Pulp and Paper Industry, Atlanta, Georgia).

"Much technical writing is ... dull, stiff, or hard to understand-because of unnecessary complexity," according to Engineered Report Writing by Melba W. Murray (Petroleum Publishing Co., Tulsa, 1969.) A short example from the book is the following sentence and revision (reprinted by permission).
"The mineralogical techniques used in these studies were those determined to be the most advantageous from a standpoint of both speed and accuracy." Meaning: the mineralogical techniques were the fastest and most accurate available.

The Style Manual for Biological Journals offers another instance (second edition, p. 10). First, the offending example:

The quantitative findings reported by Smith were analyzed and seemed, according to our interpretation, to contain significant inconsistencies. Our reasons for attaining this diverse opinion are...

The correction suggested by the manual:

I think Smith's measurements are questionable because . . .

Note the switch from "the ... findings ... seemed" to "I think." The active voice is often (but not always) the clearest means of making a statement; it should not be avoided, even when it involves the first person, merely owing to a concern for supposedly scholarly conventions. As the Style Manual of the American Institute of Physics notes, "The old taboo against using the first person in formal prose has long been deplored by the best authorities and ignored by some of the best writers. . . . The passive is often the most natural way to give prominence to the essential facts ... but avoid the passive if it makes the syntax inelegant or obscure" (third edition, p. 14).

\section{Writing the Abstract}

The abstract reports the essential information contained in the paper, including the purpose, methods, results, and conclusions. Speculations should be clearly identified as such. It is possible to convey the essential information of some well-written papers in one well-written sentence. Do not use sentences telling the reader what "is described" or what "is discussed"; the abstract is neither a sentence outline of the paper nor a summary. Concise sentences with verbs in the active voice should predominate.

\section{Other Writing Guidebooks}

Following is a brief list of writing and usage guides, roughly in the order of their usefulness.

Geowriting: A Guide to Writing, Editing, and Printing in Earth Science, edited by Wendell Cochran, Peter Fenner, and Mary Hill, American Geological Institute, Washington, D. C., 1973. An excellent manual covering writing, the mechanics of manuscript preparation, and production. Extensive bibliography.

The Elements of Style, William Strunk, Jr., and E. B. White, third edition, Macmillan, New York, 1979. Perhaps the best and most influential writing guide. 
Council of Biology Editors Style Manual, fourth edition, Council of Biology Editors, Bethesda, Md., 1978. The principles of good writing and how to apply them. Good examples.

Words Into Type, third edition, Prentice-Hall, Englewood Cliffs, N. J., 1974. Not a writing guide, but the most comprehensive editorial guide covering grammar, usage, copy preparation, and production.
A Dictionary of Modern English Usage, H. W. Fowler, second edition, Oxford University Press, New York, 1965. The most well-known, penetrating, and exhaustive guide on word usage.

The Modern Researcher, Jacques Barzun and Henry F. Graff, third edition, Harcourt Brace Jovanovich, New York, 1977. An extensive section on the craft of writing, rewriting, and copy editing.

\section{AGU PUBLICATION STYLE}

\section{A Note on Copy Editing}

Editorial staff members copy edit papers for basic grammar, clarity, and AGU style. They do not examine the more basic style or organization of the paper unless the journal editor requests it; the journal editor may also reject papers seriously deficient in clarity or precision.

The following paragraphs describe the stylistic rules under which papers are copy edited. Although AGU does not copy edit Geophysical Research Letters papers, such papers should be written to conform to the following guidelines,

\section{Principles of Reference List Style}

The purpose of the reference list and of AGU's reference style is to enable the reader to locate cited literature; accurate and complete references are therefore crucial (see Figure 1 for a sample of style in representative cases). Misspelled names, incorrect dates, or missing publisher locations defeat the purpose of the list and cast doubt on the reliability of the author. It is important to include the information necessary for the reader to obtain reports published by laboratories, companies, and government agencies. When in doubt, include too much rather than too little information. There is no uniformly accepted standard for reference list style, but AGU intends to stav abreast of trends toward such uniformity.

\section{In press}

AGU gives works accepted for publication but not yet released a full reference using the words "in press" in place of the journal volume and using the year of acceptance as the date. Manuscripts submitted for publication but not yet accepted are considered to be unpublished (see below)

\section{Meetings}

Papers presented at meetings should be described as such in the reference list. The common practice of reproducing these papers and distributing them to the meeting participants does not constitute publication. If the abstract is in the published literature, include that information in the reference.

\section{Unpublished work}

AGU does not include in the reference list personal communications, unpublished data, and manuscripts in preparation or submitted for publication because it does not consider them to be part of the literature. Refer to them in text in parentheses by first initials and last name of source, type of material, and date. If you wish, you may include the affiliation of the source, for example (J. Wilson, personal communication, 1971); (B. L. Smith, University of Massachusetts, unpublished data, 1979).

AGU does not consider preprints and reports that are not available to the public to be part of the literature. Authors may refer to them in text in parentheses by first initial and last name of author, title, institution, serial number, and date.

\begin{abstract}
Abbreviations
AGU abbreviates most titles according to the Chemical Abstracts Service Source Index. If this source is not available, check the reference list in a recent issue or spell out.
\end{abstract}

\section{Page numbers}

Use total pages when referencing books (e.g., 388 pp.) and inclusive pages when referencing complete articles in books (e.g., pp. 504-522) and periodicals (e.g., 504-522).

\section{Reference Citations}

All citations must have a corresponding entry in the reference list; all entries in the reference list must be cited in the text.

\section{Authorship}

Cite references by last name of author and year of publication in square brackets: [Smith, 1983]; cite two authors as, for example, Smith and Jones, and three or more authors as Smith et al. Cite references that have no individual authors by the sponsoring agency.

Cite publications from several years by the same author as follows: [Smith, 1975, 1977]. Cite multiple publications in the same year by the same author as follows: [Smith and Jones, $1977 \mathrm{a}, \mathrm{b}]$. In a list of citations, place unpublished material last: [Smith, 1978; Jones et al., 1980, 1982; B. Jones, unpublished manuscript, 1982].

If works by different authors with the same last name appear in the same vear, distinguish them in the text citation by using the senior authors' initials (or first names if the initials are identical, or second authors' initials if the senior authors' names are identical, etc.). If the works did not appear in the same year and there are only two or three 


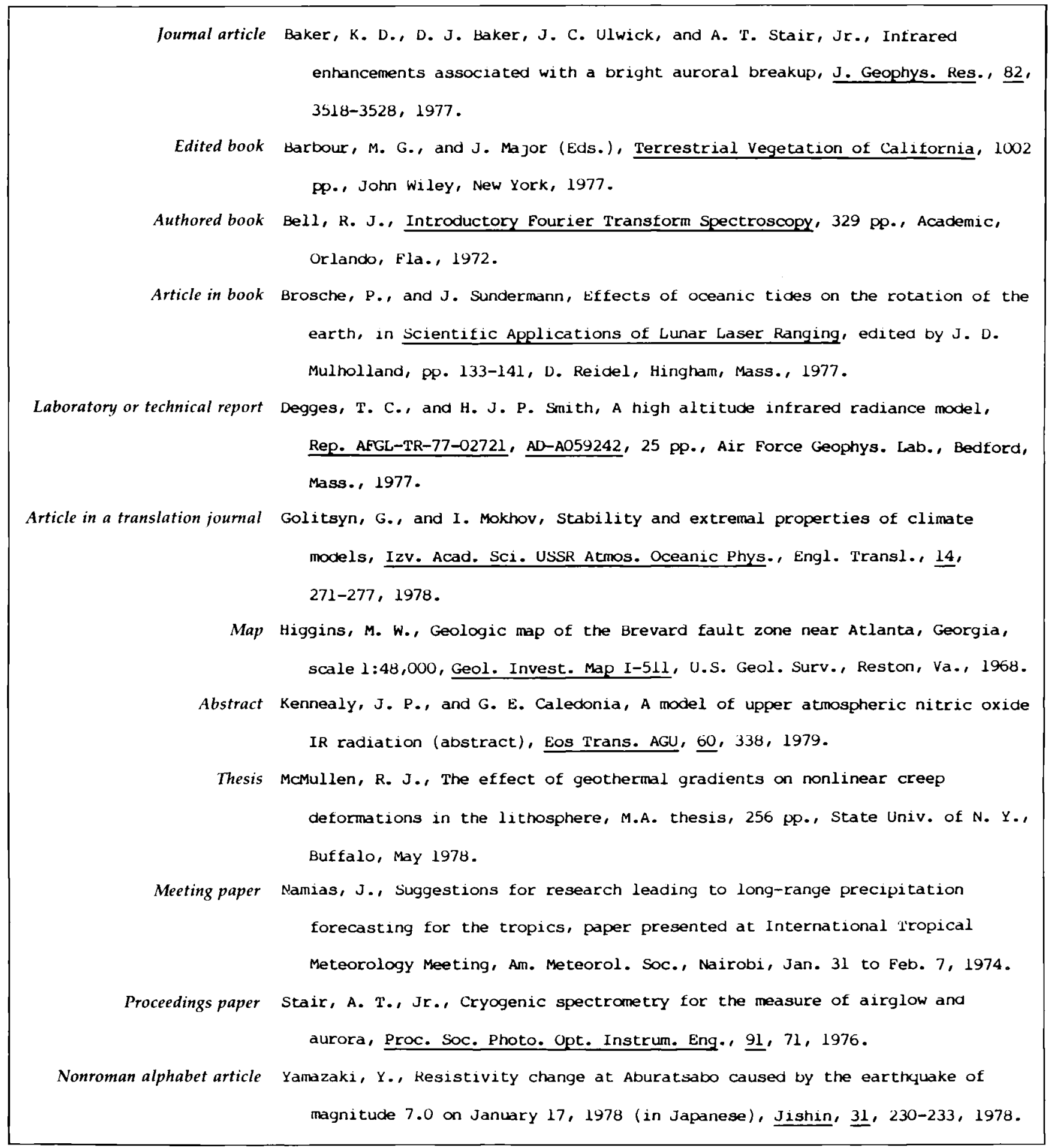

Fig. 1. A reference list in the format that should be used in manuscripts submitted for any AGU journal or book except biological works of the Antarctic Research Series. Labels are shown here only to identify common types of references. Note the space between initials of first names in the sample list. The abbreviation U.S. is closed up when used as an adjective, such as in U.S. Geological Survey.

such references, distinguishing the citations by year alone would probably be sufficient to avoid confusion.

\section{Punctuation}

If the names of the authors are part of the sentence, enclose the date in brackets; if the entire citation is parenthetical, enclose it all in brackets, separating authors from date with a comma (see sample text page).

\section{Citing parts of a reference work}

If you wish to direct the reader to different parts of a reference work at different points in your text, include the details in the citation, not in the reference list. For instance, to cite a page number, equation, or table, the citations would read [Moody and Graybill, 1963, p. 73], [Hines, 1967, equation (27)], or [Bailey et al., 1980, Table 8]. 


\section{Measure and Number}

\section{Units of measure}

All quantities must be in metric units. When giving the dimensions of equipment built to nonmetric specifications or when reporting data traditionally measured in nonmetric units, include metric equivalents. AGU recommends that authors use the International System of Units (SI) (see Tables 1 and 2). SI standards may be found in "NBS guidelines for use of the metric system" (National Bureau of Standards, Publ. LC1120, 7 pp., Dec. 1979). A more extensive guide is "The International System of Units (SI)" (NBS Spec. Publ. 330, 1977). An extensive list of conversion factors is contained in "The International System of Units: Physical constants and conversion factors (revised)," by $\mathrm{E}$. A. Mechtly (NASA Spec. Publ., SP-7012, 1969). The following guidelines apply:

1. Do not use a period with SI symbols except at the end of a sentence.

2. Use a space instead of a dot or hyphen for unit products.

3. AGU prefers negative exponents to slashes for unit

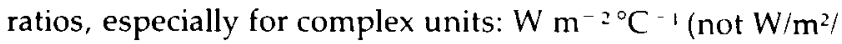
${ }^{\circ} \mathrm{C}$ ). Make usage consistent throughout text and figures.

4. Write out units of measure when they are not preceded by a numerical value (e.g., " $24 \mathrm{~m} \mathrm{~s}^{-1}$," but "a few meters per second").

5. Use 0830 UT and 0830:15 UT, not $08.5,08: 30: 15$, or $08 \mathrm{~h}$ $30 \mathrm{~m} \mathrm{15s}$. Do not use Z or Greenwich Mean Time. Spell out geomagnetic time (GMT) at first use.

TABLE 1. SI Base, Supplementary, and Derived Units and Abbreviations

\begin{tabular}{lll}
\hline \multicolumn{1}{c}{ Name } & Abbreviation \\
\hline meter & Base Units & $\mathrm{m}$ \\
kilogram & $\mathrm{kg}$ \\
second & $\mathrm{s}$ \\
ampere & $\mathrm{A}$ \\
kelvin & $\mathrm{K}$ \\
mole & $\mathrm{mol}$ \\
candela & $\mathrm{cd}$ \\
& & \\
radian & Supplementary Units & $\mathrm{rad}$ \\
steradian & & $\mathrm{sr}$ \\
& & \\
hertz & Derived Units & $\mathrm{Hz}$ \\
newton & $\mathrm{N}$ \\
pascal & $\mathrm{Pa}$ \\
joule & $\mathrm{J}$ \\
watt & $\mathrm{W}$ \\
coulomb & $\mathrm{C}$ \\
volt & $\mathrm{V}$ \\
farad & $\mathrm{F}$ \\
ohm & $\mathrm{s}$ \\
siemens & $\mathrm{S}$ \\
weber & $\mathrm{Wb}$ \\
tesla & $\mathrm{T}$ \\
henry & $\mathrm{H}$ \\
degree Celsius & ${ }^{\circ} \mathrm{C}$ \\
lumen & $\mathrm{lm}$ \\
lux & $\mathrm{lx}$ \\
becquerel & $\mathrm{Bq}$ \\
gray & $\mathrm{Gy}$ \\
\hline &
\end{tabular}

TABLE 2. Units in Use With SI

\begin{tabular}{lll}
\hline \multicolumn{1}{c}{ Name } & \multicolumn{1}{c}{ Symbol } & \multicolumn{1}{c}{ Value in SI Unit } \\
\hline minute & min & 1 min $=60 \mathrm{~s}$ \\
hour $^{*}$ & $\mathrm{~h}$ & 1 hour $=60 \mathrm{~min}=3600 \mathrm{~s}$ \\
day $^{*}$ & $\mathrm{~d}$ & 1 day $=24$ hour $=86,400 \mathrm{~s}$ \\
year & yr or a $t$ & \\
degree &, & $1^{\circ}=(\pi / 180) \mathrm{rad}$ \\
minute & $\prime$ & $1^{\prime}=(1 / 60)^{\circ}=(\pi / 10,800) \mathrm{rad}$ \\
second & $\mathrm{L}$ & $1^{\prime \prime}=(1 / 60)^{\prime}=(\pi / 648,000) \mathrm{rad}$ \\
liter & $\mathrm{t} \mathrm{L}=1 \mathrm{dm}^{3}=10^{-3} \mathrm{~m}^{3}$ \\
metric ton (tonne) & $\mathrm{t}$ & $1 \mathrm{t}=10^{3} \mathrm{~kg}^{3}$ \\
hectare & ha & $1 \mathrm{ha}=10^{4} \mathrm{~m}^{2}$ \\
\hline
\end{tabular}

*Abbreviate only when used in combination (e.g., $\mathrm{cm} \mathrm{h}^{-1}, \mathrm{~m} \mathrm{~d}^{-1}$,

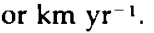

tUse only for geologic time and with SI prefixes (e.g. Ma, Ga).

6. Multiples and submultiples of $\mathrm{SI}^{\prime} \mathrm{s}$ meter/kilogram/ second units may be used. Thus centimeter is an acceptable SI unit even though it is also part of the centimeter/gram/ second system. Gram is not an acceptable SI unit; $40 \mathrm{~g}$ would be expressed in SI as $4 \times 10^{-2} \mathrm{~kg}$ or as $40 \mathrm{mkg}$ (millikilograms).

\section{Numbers in text and tables}

1. Use the following style for dates in text and tables: March 3, 1976.

2. Give ranges in full: $1956-1958$, not $1956-58$; pp. 291294, not 291-4.

3. Insert a zero before the decimal point in a number less than unity: 0.002 , not .002 .

4. Use commas in numbers of five or more digits. Do not use a comma in a four-digit number unless the comma is needed for alignment in a column.

5. Do not spell out numbers that precede units of measure ( $1 \% ; 3$ days; 2 years; $0.01 \mathrm{~m} ; 5,2.5,1$, and $0 \mathrm{mGal}$ ) except at the beginning of a sentence, in which case the unit of measure is also spelled out (Ten meters).

6. Do not use a space between a number and an algebraic quantity (16y) or between a number and the symbols of angle $\left(25^{\circ} 18^{\prime} 35^{\prime \prime}\right)$.

7. Do not spell out numbers implying arithmetical manipulation: a factor of 7; add 5; the constant 10; an increase of 3 times.

8. Spell out numbers less than 10 having no arithmetical implication: the four curves on the figure; more than nine experiments.

9. Spell out ordinals: first, not 1 st; but kth, $(k+1)$ th.

10. Spell out a number that directly precedes or follows a numeral: ten 2-m strips; 136 two-hour lectures.

11. Use arabic numerals in names of artificial satellites, rockets, etc.: Explorer 8, Vanguard 3, Surveyor 1, OGO 3.

12. Use arabic numerals for figure and table numbers: Figure 5, Table 3.

\section{Punctuation}

\section{Commas}

1. Use a comma before the conjunction in a simple series of three or more items: carbon, hydrogen, and nitrogen.

2. Use a comma before the coordinating conjunctions "and," "but," "or," and "nor" in a compound sentence. A 
compound sentence contains two clauses each of which can stand alone as a simple sentence.

The zonal component appears as the basic current, and the vertical and meridional components are perturbation quantities.

See also the section on semicolons.

3. Use a comma after a dependent clause that precedes the main clause of a sentence.

If the ionospheric electric field is increased, the drift velocity of the electrons may exceed a critical value.

4. Parenthetical words, phrases, or nonrestrictive clauses that interrupt the flow of thought in a sentence should be preceded and followed by a comma.

That possibility will not, however, be considered here.

This effect, although less pronounced, is also found in the omnidirectional fluxes.

The electric field, which is basically a function of applied potential, contains the effect of the nose geometry of the vehicle.

At Marble Point, Antarctica, meteorological observations were made from November 15, 1958, to January 27, 1959

5. Do not use a comma after introductory prepositional phrases where a natural break occurs nor after hence, thus, or therefore.

In the absence of clear measurements it became necessary to extrapolate values.

The results were uncertain; hence we did not use them.

6. Do not set off restrictive phrases or clauses.

The electric field that we have defined is a function of applied potential.

In this case the clause "that we have defined" restricts the meaning of the phrase "electric field" and therefore must not be separated from it by a comma.

\section{Semicolons}

1. Use a semicolon before the adverbial conjunctions "however," "thus," "hence," “yet," "therefore," etc., in a compound sentence.

The concentration of solute decreases with increasing temperature; therefore the brine pockets must enlarge as they advance into warmer ice.

2. Use a semicolon between independent clauses not joined by a conjunction. A semicolon should be used in this case only if the ideas in the two clauses are so closely related that a period would make too distinct a break between them.

A chain of seven riometers for measurement of ionospheric absorption is listed in Table 1; additional information may be found in Figure 1.

\section{Colons}

1. A colon should follow a complete sentence that introduces an item or list.
The data were obtained for the following periods: sunrise, noon, and sunset.

2. Do not use a colon when a list or equation comes immediately after a verb or preposition.

The data were obtained at sunrise, noon, and sunset.

\section{Miscellaneous}

1. Avoid using long dashes in place of commas or parentheses. They are a dramatic device and are usually inappropriate in technical writing.

2. Use double quotes. Use single quotes only for quotes within quotes. Put commas and periods before the closing quote mark; put semicolons and colons after it.

3. Punctuate figure captions as text.

4. Do not use punctuation at the end of displayed equations.

\section{Spelling, Hyphenation, and Abbreviations}

\section{Spelling}

AGU follows Webster's Third New International Dictionary with some exceptions. Webster's New Collegiate Dictionary is a more commonly available substitute. For geographical names, AGU follows Webster's New Geographical Dictionary.

1. Use American rather than British spelling (meter, analyze, color, reflection).

2. Use the shorter form of alternative spellings (modeled, biased, toward, sizable, acknowledgment).

3. Use minimal capitalization. AGU style must cover all geophysics disciplines, and the various capitalization schemes of each discipline cannot be followed. The lowercase form should be used for the names of temporary stations (Mirnyy station), underwater features (Hatteras abyssal plain, Cocos ridge), and oceanographic features (intertropical convergence zone, Florida current). AGU uses lowercase for earth, sun, moon, north/south pole, northern/southern hemisphere, equator. Protected trade names are capitalized, but formerly protected trade names are lowercased. Use lowercase for section 3, case 1, and experiment 5, but capitalize Figure 2 and Table 3 .

\section{Forms never hyphenated}

Do not use a hyphen for the following items, whether used as nouns or modifiers:

1. Noun-noun compounds (boundary layer, data processing, plasma flow), foreign phrases (in situ, en echelon), and adverbs ending in -ly and -ward (slowly rising, northward trending). However, see item 4 in the section below on forms always hyphenated.

2. Compounds used frequently as both nouns and adjectives (solar wind, $F$ region, $X$ ray, steady state).

3. Prefixes (semiempirical, subsolidus, corotate, nonlinear, reenter).

4. Satellite names such as Voyager 2 and ATS 6 (but AE-C and S3-3).

\section{Forms always hyphenated}

Use a hyphen for the following items:

1. Noun-participle and adjective-participle compounds 
used as adjectives (sulfate-containing aerosol, coarse-textured grain) but not in the predicate (are coarse textured).

2. Temporary compounds indicating number, dimension, or quality used as adjectives (25-channel recorder, three-dimensional model, second-order equation, multiplelayer model, high-energy particles, smaller-scale features, medium-range missile).

3. A numeral plus simple unit of measure used as an adjective (20- $\mathrm{m}^{2}$ area, 5-year-old data, 2-GPa pressure) but not when the unit is complex ( $3 \mathrm{~m} \mathrm{~s}^{-1}$ velocity).

4. Words of equal weight used as an adjective (air-sea interface, pressure-temperature plot).

\section{Abbreviations}

1. Identify abbreviations where they are introduced. See Table 3 for AGU's style of abbreviating some commonly used expressions; these abbreviations need not be identified at first use.

2. Do not abbreviate the names of organizations in reference lists; AGU will abbreviate according to house style.

3. Write out names of months and the word "figure" throughout the text. Names of months may be abbreviated only in tables, but note that the months March through July must always be written out.

4. Do not use symbols as a substitute for words in text. For example, in text, write out the words "asterisk," "plus or minus," and "greater than," rather than using the symbols ${ }^{*}, \pm$, and $>$.
TABLE 3. Selected Abbreviations and Symbols: Definition and Use

Definitions and Use

\begin{tabular}{|c|c|}
\hline A & ampere \\
\hline$\AA$ & angstrom \\
\hline ac & alternating current \\
\hline A.D. & Anno Domini (e.g., A.D. 1420) \\
\hline $\mathrm{AE}-\mathrm{C}$ & Atmosphere Explorer C \\
\hline$a p$ & planetary geomagnetic range index, 3-hour interval \\
\hline$A p$ & planetary geomagnetic range index, daily average \\
\hline B.C. & before Christ (e.g., 1125 B.C.) \\
\hline B.P. & before present (e.g., $10^{7} \mathrm{~m} . \mathrm{y}$. B.P.) \\
\hline cf. & compare (no comma) \\
\hline CIRA & COSPAR international reference atmosphere \\
\hline $\mathrm{cm}^{3}$ & cubic centimeter (use instead of " $\mathrm{cc}^{\prime \prime}$ ) \\
\hline d & $\begin{array}{l}\text { day, only in combination with other units; write out } \\
\text { otherwise }\end{array}$ \\
\hline $\mathrm{dB}$ & decibel \\
\hline dc & direct current \\
\hline Dst & $\begin{array}{l}\text { variation of magnetic storm as a function of storm } \\
\text { time only }\end{array}$ \\
\hline$E_{\mathrm{sut}}$ & equatorial sporadic $E$ \\
\hline et al. & $\begin{array}{l}\text { and others (use in text citations for more than two } \\
\text { authors) }\end{array}$ \\
\hline$F_{2}$ & region or layer \\
\hline$f_{0} F_{2}$ & ordinary frequency of $F_{2}$ layer \\
\hline (g) & gas (e.g., $\left.\mathrm{H}_{2} \mathrm{O}(\mathrm{g})\right)$. \\
\hline GMT & $\begin{array}{l}\text { Greenwich mean time (use UT instead); } \\
\text { geomagnetic time }\end{array}$ \\
\hline h & $\begin{array}{l}\text { hour, only in combination with other units; write } \\
\text { out otherwise }\end{array}$ \\
\hline $\mathrm{Hz}$ & hertz \\
\hline $\mathrm{K}\left(\right.$ or $\left.^{\circ} \mathrm{K}\right)$ & kelvin \\
\hline$K p$ & planetary geomagnetic range index, 3 -hour interval \\
\hline $\mathrm{L}$ & liter \\
\hline (1) & liquid (e.g., $\mathrm{H}_{2} \mathrm{O}(1)$ ) \\
\hline$m$ & molal (e.g., $1.5 \mathrm{~m}$ ) \\
\hline$M$ & molar (e.g., $1.5 \mathrm{M})$ \\
\hline msl & mean sea level \\
\hline$N$ & normal (e.g., $3 N$ ) \\
\hline $1 \mathrm{NG}$ & first negative group \\
\hline O II & ionization state of oxygen \\
\hline Pc & continuous geomagnetic micropulsations (e.g., Pc 2) \\
\hline$p \mathrm{H}$ & acidity or alkalinity indicator \\
\hline $\mathrm{Pi}$ & irregular geomagnetic pulsation (e.g., Pi 2) \\
\hline
\end{tabular}

\section{PREPARING FIGURES}

AGU will accommodate foldouts, maps placed in a separate pocket, or color photographs if the journal editor deems this presentation essential; the extra costs must be borne by the author's institution.

All black and white continuous-tone figures and line drawings without exception are printed on the same paper as journal text.

If you are using figures copyrighted by others, submit with your paper letters of permission from the copyright owners.

\section{Planning Figure Preparation}

Clear figures with captions fully describing their contents are often the most efficient means of presenting data. Indeed, in recent years, about one third of all space in the Journal of Geophysical Research has been devoted to graphs and other illustrations, and AGU encourages its manuscript reviewers to suggest improvements to figures as well as to text.

Keep in mind the following points when planning the design and presentation of your figures:

1. Oversized figures must be capable of withstanding reduction. A reducing photocopier is often useful in judging how well the characters and lines on an original will retain their legibility.

2. Make the quantitative information in the figure stand out.

3. Avoid cluttering the figure with too many labels; if there are many symbols, translate them in a separate, legend section of the figure or in the figure caption.

4. Clearly and completely describe figures in the combined information of the figure caption and the paper's text.

5. Strive to make the figure caption as informative as possible. First, describe what is in the figure, then draw the 
reader's attention to salient features of the display, and then briefly state the importance of these features.

Any of the following conditions will cause AGU to return figures to the author for redrafting:

- Hand-drawn lines or lettering

- Lettering too large or too small to permit appropriate reduction

- Dot pattern too faint or too fine to be picked up by camera

- Faint or broken lines or lettering

- Any part of figure executed in pencil or colored ink (only black ink should be used)

The following conditions are frequent problems with computer-generated figures and occur in other types of graphs as well:

- Axis labeling far too large in proportion to the rest of the figure

- An excessive number of axis demarcations

- An excessive number of significant figures in the axis numbers

- Labeling in the figure which would be better symbolized and translated in a legend section of the figure or in the caption

\section{Preparing and Submitting Figures}

Each figure should be a sharply focused photograph or computer-generated figure on $8.5 \times 11$ inch $(21.5 \times 28 \mathrm{~cm})$ paper. Xerographic copies are not acceptable for reproduction purposes. Authors are discouraged from submitting original mechanical drawings. AGU will not accept responsibility for the safety of such figures and will not return them to authors unless a specific written request accompanies the figures.

The space available on the printed page for figure plus caption is $12.1 \times 20.7 \mathrm{~cm}(16.5 \times 21.5 \mathrm{~cm}$ for Radio Science and $16.1 \times 21.5 \mathrm{~cm}$ for Tectonics, Global Biogeochemical $\mathrm{Cy}$ cles, and Paleoceanography). Draft your figures so that when reduced to final publication size, the height of the lettering will meet the following dimensions:

- Numbers demarcating graph axes: $1.5 \mathrm{~mm}$

- Other labels on graph: $0.75 \mathrm{~mm}$ minimum; $3 \mathrm{~mm}$ maximum

- If no axis demarcations: $1.5 \mathrm{~mm}$ for numbers or capital letters.

AGU copy editors will specify reductions of figures to achieve the above character sizes. Authors who desire particular figure layouts or sizes within the limits described here should specify their requirements in the manuscript. Authors who wish to submit figures already reduced to the final publication specifications outlined here should contact the AGU publications office before preparing such reductions.

Two or more figures intended to convey data at the same scale should be drawn to allow reduction at the same percentage for reproduction.

If photographs contain extraneous areas, AGU excludes such areas in the reproduction of the photograph.

\section{PREPARING THE MANUSCRIPT}

\section{Title Page and Author Address List}

Figure 2 illustrates a sample title page. If there are more than three affiliations associated with authorship of the paper, list them in footnotes at the bottom of the page, each keyed to the author's name. Affiliations typically contain the division or department of an institution and the institution name and location. Following the references, list all authors (alphabetically) and their mailing addresses.

Choose a short title that requires no more than 60 characters, including punctuation and spaces. This short title will be preceded by author names and will be printed at the top of each page of the published article.

\footnotetext{
Abstract

Write the abstract in a single paragraph with fewer than 250 words and no displayed mathematics or tables. Do not cite references, tables, or figures; do not use unfamiliar terms or abbreviations (unless defined at first use) or trade names.
}

\section{Text}

\section{General format}

Refer to Figure 3. Indent the first line of paragraphs and do not use extra space between paragraphs. A paragraph, representing a progression of thought, should contain more than one sentence. Do not highlight words or phrases in text through such means as italics or underscoring. Such emphasis must be conveyed by explicit statements rather than by typographical devices.

\section{Footnotes}

Do not use footnotes. Owing to the problem they create in page makeup, footnotes must be worked into text or deleted.

\section{Subheadings}

AGU uses four levels of heads in text, illustrated in Figure 3. In practice, each level must be used more than once under its immediately preceding superior head. For instance, in the sample, in order for the grade 2 head "Focal Mechanism of the Main Shocks" to stand, another grade 2 head would have to follow it before a new grade 1 head could be introduced. 
Do not use section numbers with subheadings unless they are cross-referenced in text. Use the "decimal" system (1.1, 1.1.1, etc.) for cross-referenced heads.

\section{Figure and table citations}

Each figure and table must be cited at its appropriate point in text as Figure 1, Figure 2a, Table 1, etc. Citations must be in numerical order; for example, even if you mention Figure 5 before citing Figure 4, you must also cite Figure 5 after citing Figure 4.

\section{Mathematics}

\section{Identifying characters and typefaces}

All mathematical characters in the manuscript that are available on a standard typewriter must be typewritten in displayed equations as well as in text. Use Greek or math typewriter fonts when available.

Identify each character that has been handwritten in the manuscript by inserting a note in the margin at the character's first use on each page. AGU will charge authors of AGU-produced papers for all corrections in galley proof of material that was handwritten in the manuscript.

In AGU-produced papers, identify at every occurrence in math the typewritten letter 1 and numeral 1 and the typewritten letter $O$ and the numeral 0 . AGU will charge authors of such papers for all corrections of these typewritten characters that were not identified in manuscript.

\section{Variables}

Do not use italic type in the manuscript; variables in AGU-produced papers will be set in italic by the typesetter. Identify by a note in the margin the name of any special typefaces (boldface, script, or sans serif) desired for mathematics.
Avoid using words or phrases as variables; single letters or Greek characters should be substituted. (Example: REL $=$ SUM1 + SUM2 + SUM3 should become R $=S_{1}+S_{2}+$ S3.)

\section{Subscripts and superscripts}

Clearly place subscripts and superscripts in their appropriate positions. To avoid overlapping, type subscripts to precede superscripts: $b_{1}{ }^{2}$.

\section{Accents}

Symbols that are not available for AGU-produced papers and therefore must not be used are triple dots, any accents (other than bars) that extend over more than one character, and double accents (e.g., a circumflex over a bar). Authors can eliminate accents over characters by using such symbols as the prime (') and asterisk (*).

\section{Exponentials and fractions}

Use exp rather than e if the argument of the exponential is complicated or lengthy. Fractional exponents should be used instead of radical signs. Avoid awkward fractional composition by introducing negative powers. In text, use shilling-mark fractions $(1 / r)$ and enough parentheses, brackets, and braces to avoid ambiguity; use them in the order $\{[()]\}$.

\section{Equation numbering}

Displayed equations that are referred to in the paper must be numbered consecutively throughout the paper; the number (in parentheses) should be to the right of the equation. Appendix equations may be numbered either consecutively with text equations or as (A1), (A2), etc

\section{Notation list}

In papers containing complex and lengthy mathematics, authors should provide an alphabetized notation list directly preceding the acknowledgments.

\section{Solar Polar Coronal Holes and Galactic Cosmic Ray Intensities}

$$
\text { S. P. Agrawal and L. J. Lanzerotti }
$$

Bell Laboratories, Murray Hill, New Jersey

D. Venkatesan

Department of Physics, University of Calgary, Alberta

R. T. Hansen

National Center for Atmospheric Research, Boulder, Colorado

Short title: Coronal Holes and Galactic Cosmic Rays

Fig. 2. Sample title page in manuscript form. 


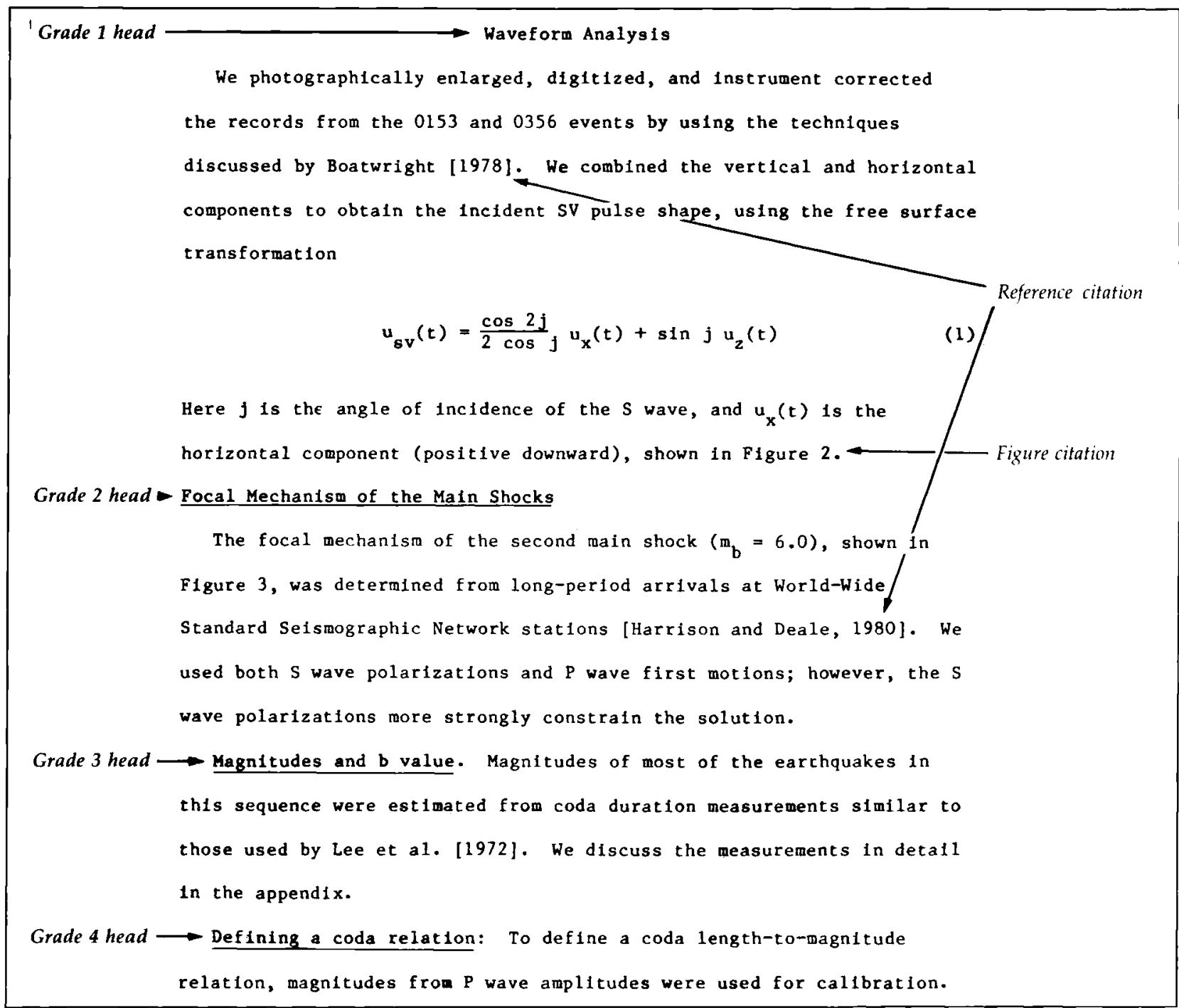

Fig. 3. Sample text page in manuscript form.

\section{Appendixes}

Avoid appendixes consisting of tables or figures with little or no text. Such tables or figures should be enumerated in sequence with other text tables or figures. Also consider whether such material is suitable for microfiche archiving.

\section{Acknowledgments}

Acknowledgments should be limited to collegial and financial assistance. They are not meant to recognize personal or manuscript-production support. AGU does not use titles such as "Dr." or "Professor" in the acknowledgments or elsewhere in research papers.

\section{Organizing the Reference List}

Type the reference list with double or triple spacing throughout (Figure 1 illustrates a sample list and shows the elements to be included in various types of references).

Organize the reference list by strict letter-by-letter alphabetization of the first item in the reference, as in the sequence of Lane, Le Pichon, Macaulay, MacDonald, McDonald, Sanders, Sandia National Laboratories, St. Amant, Urey, von Seggern.

List references by the same first author in the following order: first author alone, chronologically; one coauthor, alphabetically by coauthor and then chronologically; two or more coauthors, chronologically. Use only initials for first names. The following list illustrates this sequence.

Smith, A., ..., 1969a.

Smith, A., ..., 1969b.

Smith, A., ..., 1971.

Smith, A., and C. Allen, ..., 1972.

Smith, A., and B. Frank, . . , 1968.

Smith, A., and B. Frank, ..., 1970.

Smith, A., L. Roberts, and T. Jones, . . . 1977.

Smith, A., T. Jones, and L. Roberts, . . . 1978.

Alphabetize different first authors having the same last name according to the initials of their first names. If their initials are the same, alphabetize them by their full names or by the last names of the second authors if they exist. See the section above on reference citations for the method of distinguishing the citations of such works. 


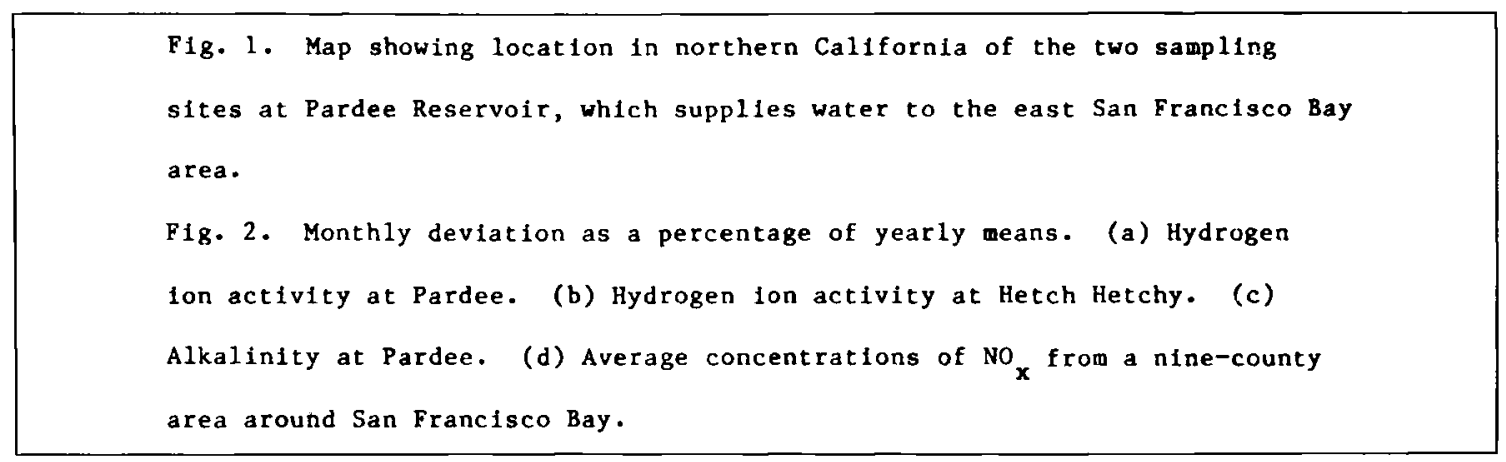

Fig. 4. Sample figure caption list in manuscript form. In the second caption, note the style for the treatment of figure parts.

\section{Figure Captions List}

Type all captions together in a double-spaced or triplespaced list (see Figure 4). Do not attach captions to figures. Note the treatment of figure parts in the sample captions.

\section{Tables}

1. Capitalize the initial letter of each major word of the title. Keep the title short (see Figure 5).

2. Use three horizontal rules: one below the title, one below the column heads, and one below the last line of data. Use straddle rules for complex heads.

3. Use no vertical rules.

4. Place all footnotes below the last horizontal rule. Do not key general footnotes to the table title; such notes have no key and precede all keyed footnotes. Indicate keyed footnotes with symbols (asterisk, dagger, etc.) or lowercase letters typed as superscripts; do not use numbered footnotes. Footnote order is left to right, then top to bottom.

5. Each table must have at least two columns, and all columns except the first must have a head.

6. Center data under each column heading.

7. Use commas in numbers of five or more digits to the left of the decimal point. Use commas in numbers of four digits to the left of the decimal point for alignment in a column that contains five-digit numbers.

8. Insert a zero before the decimal point in a number less than unity: 0.002 , not .002 .

9. Use the following style for dates: Sept. 5, 1980 (but spell out months in text). Always spell out the months March through July.

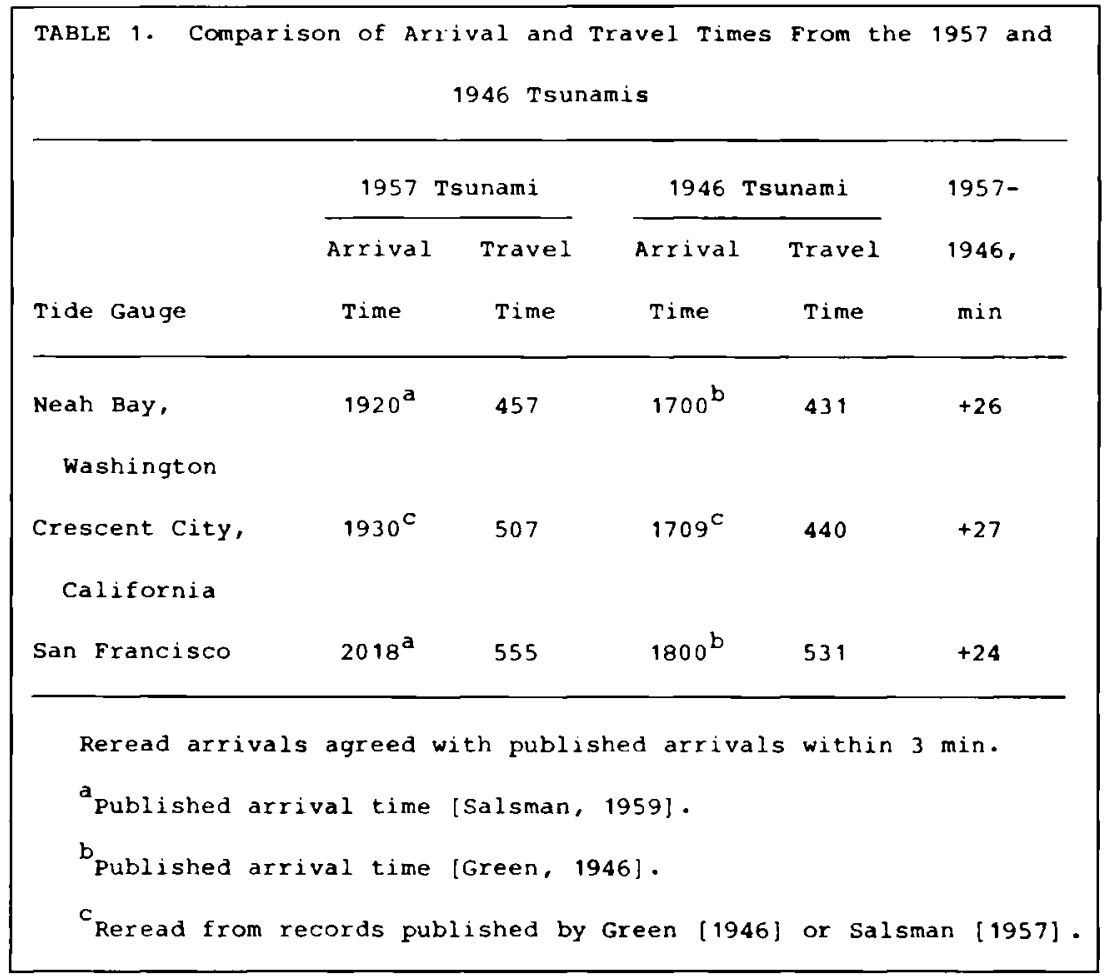

Fig. 5. Sample table in manuscript form. 